\title{
EDUCAÇÃO AMBIENTAL COMO FERRAMENTA PARA O CONTROLE DO CONSUMO DE PRODUTOS GERADORES DE RESÍDUOS
}

\author{
Arlinda Maria Rodrigues do CARMO \\ Kátia Regina BENATI ${ }^{2}$
}

\begin{abstract}
Resumo
Este artigo busca apresentar informações de como a Educação Ambiental pode tornar-se uma ferramenta necessária para controle do consumo de produtos geradores de resíduos. O processo de construção dessa análise perpassa pelo entendimento da necessidade de promover a sustentabilidade, buscando atender dentro de uma visão mais ampla os Objetivos do Desenvolvimento Sustentável (ODS) da Organização das Nações Unidas (ONU). O intuito é averiguar como a Educação Ambiental ao atingir diversos públicos em suas diversas modalidades, tendo como destaque o âmbito formal, pode colaborar com sua valiosa oferta de conhecimentos para minimizar o avanço da degradação ambiental.
\end{abstract}

Palavras-chave: Educação Formal. Impacto Ambiental. Sustentabilidade.

\footnotetext{
${ }^{1}$ Mestra em Planejamento Ambiental - Universidade Católica do Salvador. Professora da Rede Pública de Ensino do Estado da Bahia. Orcid: https://orcid.org/0000-0001-6029-7721.

E-mail: arlinda.carmo@hotmail.com.

2 Doutora em Ecologia - Universidade Federal da Bahia. Professora Permanente do Programa de Pós-Graduação em Planejamento Ambiental e Professora do Curso de Ciências Biológicas - Uviversidade Católica do Salvador. Pesquisadora do Centro de Ecologia e Conservação Animal. Orcid: https://orcid.org/0000-0001-7964-1094.

E-mail: katiabenati@yahoo.com.br.
} 


\title{
ENVIRONMENTAL EDUCATION AS A CONSUMER CONTROL TOOL FOR WASTE GENERATORS
}

\author{
Arlinda Maria Rodrigues do CARMO \\ Kátia Regina BENATI
}

\begin{abstract}
This article presents information on how Environmental Education can become a necessary tool to control the consumption of waste products. This analysis considers the need to promote sustainability to meet within a broader view the Sustainable Development Goals (SDGs). The objective is to learn how Environmental Education, that reached different audiences in its different modalities and highlights the formal scope, can collaborate with its valuable offer of knowledge with minimizing the progress of environmental degradation.
\end{abstract}

Keywords: Formal education. Environmental Impact. Sustainability. 


\title{
ENVIRONMENTAL EDUCATION AS A CONSUMER CONTROL TOOL FOR WASTE GENERATORS
}

\author{
Arlinda Maria Rodrigues do CARMO \\ Kátia Regina BENATI
}

\begin{abstract}
Resumen
Este artículo presenta información de la Educación Ambiental como una herramienta para el control en el consumo de productos desechables. El proceso de construcción de este análisis pasa por la comprensión de la necesidad de sustentabilidad, buscando satisfacer dentro de una visión más amplia los Objetivos de Desarrollo Sustentable (ODS) de la Organización de las Naciones Unidas (ONU). El objetivo es conocer cómo la Educación Ambiental puede llegar a diferentes públicos en sus distintas modalidades, con énfasis en la educación formal, colaborando para contener el avance de la degradación ambiental.
\end{abstract}

Palabras clave: Educación formal. Impacto Ambiental. Sustentabilidad. 


\section{Introdução}

O avanço dos impactos ambientais no cenário atual corrobora para a necessidade de propagação e incorporação da Educação Ambiental aos diversos segmentos da sociedade. A necessidade de articulação, ampliação e de luta na busca de soluções para a degradação ambiental que é enfrentada na atualidade, ressalta a importância da necessidade de uma análise crítica, histórica, política, social e cultural da questão (DIAS, 2001).

A inserção e o desenvolvimento de trabalhos de Educação Ambiental, nas diversas modalidades de ensino, tornam-se elementos indispensáveis para a transformação da sociedade, cujo trabalho interferirá na formação de cidadãos conscientes e críticos, aptos, decididos e atuantes na realidade socioambiental (CAVALCANTI, 2010).

Esse desafio configura-se de modo complexo na organização do trabalho pedagógico na escola como um todo, expressando as problemáticas de vida que a escola e os estudantes querem compreender e as possibilidades de intervenção em sua realidade. A concepção de educação e escola, que sustenta essa formação de organização do trabalho pedagógico, está referenciada no materialismo histórico-dialético, que é um método de análise que permite uma compreensão dos fenômenos sociais, em sua essência e complexidade, ao mesmo tempo em que constitui um método de ação com vistas à transformação da realidade (LOURENÇÃO; RASNHESKI; MACHADO, 2019).

Esse estudo pretende analisar de que forma a Educação Ambiental pode colaborar para a sustentabilidade, a partir do entendimento de que é possível a escola propor a formação para a transformação, ainda que o fazer pedagógico na atual forma escolar esteja a serviço do capital homogeneizador totalizante. Nesse sentido, abordaremos a respeito do aparato legal que condiciona todo esse processo, considerando a Educação Ambiental como instrumento de transformação e os constantes desafios enfrentados por ela, principalmente no âmbito escolar, assim como a necessidade de se repensar a produção de resíduos, visando ambientes mais sustentais.

\section{Material e Métodos}

O estudo foi desenvolvido seguindo os preceitos de um estudo qualitativo, portanto, trata-se de uma análise sistematizada desenvolvida com base em material publicado em livros, revistas, jornais, redes eletrônicas, etc. (VERGARA, 2010).

A pesquisa dos artigos científicos foi realizada entre maio de 2019 e novembro de 2019. Para o levantamento bibliográfico, foram realizadas buscas eletrônicas por artigos em português e espanhol, publicados nos últimos 6 anos (2014- 2019) em banco de dados online, Periódicos da 
Coordenação de Aperfeiçoamento e Ensino Superior (CAPES), que incluiu a busca nas bases de dados no Scielo e Google Acadêmico, sendo este último a fonte principal da pesquisa, onde foram encontrados 46 artigos. Os temas utilizados nas buscas foram: Educação Ambiental, Resíduos, Sustentabilidade. Para a seleção das fontes, foram consideradas como critério de inclusão as bibliografias que abordassem os temas acima citados e foram excluídas todas as bibliografias deste que não estivam relacionados ao tema de estudo.

\section{Educação Ambiental como ferramenta de transformação}

Ampliar a leitura de mundo, dando condições aos educandos para aprenderem a se tornar cidadãos socialmente críticos e engajados, é extremamente relevante para formar sujeitos transformadores do contexto e da realidade onde vivem; daí a necessidade de uma formação de cunho interdisciplinar para a apreensão da interconectividade complexa dos problemas da realidade do ambiente (FREIRE, 1996).

A Educação Ambiental tem como uma de suas propostas, ofertar ferramentas que possibilitem criar redes de conhecimentos capazes de formar cidadãos conscientes do cuidado com o meio ambiente. É preciso deixar o papel de azêmolas, ao falar sobre a pedagogia adotada na operacionalização das atividades de Educação Ambiental:

A forma pedagógica de operacionalizar os programas, por sua vez precisa de amálgama certo de vários processos que vão ocorrer simultaneamente. A pedagogia liberal, que defende a predominância dos Interesses e liberdades individuais na sociedade, vem dando lugar a uma tendência pedagógica progressiva, crítica e libertadora, preconizada por Paulo Freire. Acreditamos ser a mais adequada às nossas necessidades. Precisamos urgentemente, passar da condição de azêmolas para dinâmicos insubmissos (DIAS, 2001, p. 216).

Esse amálgama, tão necessário à construção de pontes que possam vir a possibilitar uma nova forma de pensar e agir, é um grande desafio para a educação, uma busca que possibilite desconstruir e construir um novo pensar a respeito das várias questões que envolvem o comprometimento das matérias primas.

Para enfrentar esse desafio e colaborar para o fortalecimento da cidadania é necessário que cada indivíduo tome conhecimento de que é portador de direitos e deveres, e, portanto, coresponsável na defesa da qualidade de vida. Neste contexto a Educação Ambiental, surge como uma política componente de uma cidadania abrangente está ligada a uma nova forma de relação ser humano/natureza, e a sua dimensão cotidiana leva a pensá-la como somatório de práticas e 
consequentemente, entendê-la na dimensão de sua potencialidade de generalização para ação ambiental (MACEDO; RAMOS, 2015).

É fundamental situar que essas políticas não podem ser entendidas a partir da submissão à lógica utilitarista de vinculação irrestrita às demandas do processo produtivo. O redimensionamento do papel da escola, sobretudo a pública, enquanto agência de formação, não deve vincular-se meramente à lógica do mercado de trabalho. Entende-se neste contexto, a educação como elemento constitutivo das relações sociais. Essas considerações trazem complicações para a análise da escola na medida em que esta é sempre resultante de projetos de sociedade em disputa (FERREIRA, 2011).

A Educação Ambiental inserida nas práticas escolares pode significar, portanto, a inserção da escola e dos saberes que se processam em seu interior num movimento de análise e reflexão profunda do sentido de estar no mundo, vendo-o como potência e possibilidade. Educação Ambiental significa educar com a perspectiva da projeção da vida. Para tanto, impõe-se uma escola capaz de se organizar através de diálogos com a realidade, sendo críticos e propositivos com base na autonomia de ideias e práticas que se entrelaçam permanentemente (JACOBI, 2003).

No momento atual, a Educação Ambiental pode se tornar uma ferramenta importante, tendo conhecimento dos valores e ações que os sujeitos possuem frente ao meio ambiente será capaz de elaborar propostas que venham a atingir grande parte da sociedade, visando provocar mudanças mais efetiva que contribuam para a sustentabilidade socioambiental. Nesse contexto, é fundamental a formação de profissionais que atendam com eficiência à resolução dos problemas ambientais e que evidenciem esforços no sentido de promover o desenvolvimento sustentável (OLIVEIRA; CORONA, 2008).

É preciso ratificar que os conflitos ambientais não serão resolvidos pelo poder científico da economia ou da ecologia, senão através dos sentidos existenciais de valores culturais e de estilos de desenvolvimento diferenciados, nos quais a exploração, a conservação, ou o uso sustentável dos recursos dependem dos significados sociais atribuídos a ele. Essa visão só poderá ser modificada pela desconstrução da racionalidade capitalista e da aproximação com os saberes tradicionais através da busca por valores éticos e conhecimentos práticos (LEFF, 2000).

É de fundamental importância a mobilização da sociedade na busca da reflexão em prol de um sistema equilibrado que garanta a sobrevivência imediata sem esquecer as futuras gerações. Portanto a Educação Ambiental reforça esse entendimento, partindo do princípio de que esse conhecimento é instrumento indispensável para lidar com a questão ambiental no sentido de 
influenciar a abertura de caminhos que favoreçam o engajamento e a luta de todos em busca de soluções para os problemas ambientais.

\section{Produção de Resíduos, Educação Ambiental, Escolas e Sustentabilidade}

A compreensão sobre resíduo perpassa por tudo aquilo que sobra de uma atividade qualquer, ou seja, aquilo que popularmente é chamado de "lixo". No entanto, há de compreender que nas atividades humanas são gerados resíduos e não lixo. Como resíduos tais materiais possuem valores sociais, econômicos e ambientais que podem ser reaproveitados, a partir do descarte através de coleta seletiva e consequente envio para reciclagem, ou até mesmo para a geração de energia. Mas, quando descartado de forma comum, os resíduos podem virar lixo (LOGAREZZI, 2004).

De forma geral, a humanidade produz mais de 2 bilhões de toneladas de resíduos por ano (ONU, 2018). O brasileiro gera, em média, um quilo de resíduo por dia. A produção de resíduo no Brasil tem avançado em ritmo mais rápido do que a infraestrutura para lidar de maneira adequada com ele, ou seja, a produção aumenta, mas a destinação adequada, a reciclagem, a recuperação, não acompanham esse crescimento. Em 2018, o país produziu, em média, 79 milhões de toneladas de resíduo, uma variação de pouco menos de $1 \%$ em relação ao ano anterior; a tendência de crescimento na geração de lixo no país deve ser mantida nos próximos anos. Estimativas realizadas com base na série histórica mostra que o Brasil alcançará uma geração anual de 100 milhões de toneladas por volta de 2030. Esses dados revelam a necessidade de aumentar os esforços para mudar o padrão de consumo e diminuir o excesso de resíduos. E como a coleta seletiva está distante de ser universalizada, o processo de sensibilização é a primeira etapa para fortalecer essas práticas, que se tomadas em conjunto com outras medidas tendem a colaborar para proteger a saúde das pessoas e o meio ambiente contra danos e degradações (ABRELPE, 2019).

Compartilhar mudanças, fazer pequenos ajustes em nossos estilos de consumo, usando alternativas para os itens plásticos descartáveis, como garrafas, copos, pratos e talheres, e fazendo um esforço consciente para reciclar corretamente e recuperar produtos quebrados, em vez de simplesmente jogá-los fora, minimizar a forma desigual de distribuição dos bens na sociedade atual. Por meio da ação coletiva, podemos alcançar um mundo que é mais limpo, mais verde, mais seguro, mais saudável e mais feliz, para nós vivermos, trabalharmos e nos divertirmos (ONU, 2018).

O aumento do descarte de resíduos surgiu em meados dos anos de 1930, com a chamada “obsolescência programada” uma saída para os países capitalistas que viam suas economias estagnadas após a grande crise que ocorreu em 1920, a medida desesperada tomada por esses 
fabricantes foi diminuir o ciclo de vida útil de seus produtos, ocasionando assim a compra de novos bens pela população e movimentando a economia. Atualmente, a indústria mundial vive em constante desenvolvimento e inovação, produz novos produtos que, eventualmente, se espalham por todo o comércio. A oportunidade da obsolescência programada a ser aplicada se instaura em meio a boas propagandas e novidades de mercado, junto da diminuição da vida útil de um produto, ocasionando um desgaste acelerado do mesmo e assim a perda de suas funções.

Uma maneira ágil de se combater a obsolescência programada, seria a informação e a conscientização da população em geral, levar alternativas de consumo ecologicamente correto, tendo em vista que muitas pessoas compartilham de tal prática pelo desconhecimento, já que é um mal que afeta não apenas o bolso do consumidor mais também o meio ambiente no momento do descarte (HUSS; SALOMÃO; COSTA, 2019). A intensificação do consumo e da descartabilidade produz efeitos inequívocos sobre a geração de resíduos sólidos e sobre a degradação dos recursos naturais, razões que tornam sua consideração indispensável no debate ambiental, no planejamento da gestão dos resíduos sólidos e na compreensão das possibilidades de a Educação Ambiental a se desenvolver nesse contexto (LIMA, 2015).

O aumento incessante da geração de resíduos sólidos e rejeitos urbanos é uma das razões para que a destinação ambientalmente inadequada destes, de acordo com a Lei $n^{\circ}$ 12.305/2010 que institui a Política Nacional de Resíduos Sólidos (PNRS), seja um grande transtorno para o país. Diante da necessidade de reduzir os impactos ambientais promovidos pela má gestão dos resíduos sólidos, assim como pelo uso indiscriminado dos recursos naturais disponíveis, se faz indispensável a busca por ações que possam conscientizar a população brasileira, visando a construção de uma cidadania ambiental (ANDRADE, 2014).

A partir de agosto de 2010, baseado no conceito de responsabilidade compartilhada, a sociedade como um todo - cidadãos, governos, setor privado e sociedade civil organizada - passou a ser responsável pela gestão ambientalmente adequada dos resíduos sólidos. Os governos federal, estaduais e municipais são responsáveis pela elaboração e implementação dos planos de gestão de resíduos sólidos, assim como dos demais instrumentos previstos na Política Nacional de Resíduos Sólidos (BRASIL, 2010).

Sobre a questão dos resíduos sólidos muitos se perguntam qual a relação da produção de resíduos no ambiente social com o ambiente escolar. A escola é o espaço de formação de futuros cidadãos, portanto, é necessário identificar, como eles estão colaborando para geração desses resíduos bem como está sendo elaborada a sua forma de descarte. Reduzir a geração de resíduos e 
sua periculosidade, assim como o desperdício de matérias-primas, demanda respostas urgentes. Estas implicam em mudanças dos padrões existentes de produção e consumo da sociedade, na implantação de um gerenciamento integrada e sustentável dos resíduos sólidos, economicamente equilibrado, ambientalmente eficiente e socialmente justo (JACOBI, 2003).

Sendo assim, a escola pode ser considerada como o local ideal para a aplicação da relação entre meio ambiente e sociedade, já que está apresenta a possibilidade de formação de uma sociedade mais crítica e criativa, que possua uma visão mais ampla sobre as questões ambientais. Nesse contexto, a Educação Ambiental possui um papel fundamental, uma vez que possibilita a solução de diversas problemáticas e proporciona à população novas ideias, além de desenvolver valores e proporcionar soluções sustentáveis para mitigar os problemas ambientais (DIAS, 2001).

O princípio fundamental da política para Escolas Sustentáveis é que as escolas de educação básica brasileira se transformem em “incubadoras de mudanças”, onde deverão encontrar possíveis soluções para as dificuldades encontradas. A proposta busca, a partir de espaços educadores sustentáveis, incentivarem a investigação, pesquisa, descoberta, autonomia, sonhos e possibilidades, assim como o pensamento crítico e inovador. É uma proposta ousada que estimula a liberdade de escolhas, na qual cada instituição decidirá com sua comunidade o melhor caminho em busca da sustentabilidade

A Lei $n^{0}$ 9.795/1999, a qual institui a Política Nacional de Educação Ambiental (PNEA), surge como projeto de atuação governamental, que buscou efetivar a implementação da Educação Ambiental devendo para isto ser desenvolvida e concretizada por meio da ação de órgãos e instituições, inclusive por órgãos públicos da União, Estados, e Municípios. Portanto, enfatiza a necessidade de fortalecer os processos pelos quais a sociedade constrói conhecimentos, habilidades, valores sociais, atitudes e competências acerca da conservação do meio ambiente.

A Política Nacional de Educação Ambiental também destaca que a Educação Ambiental faz parte da educação nacional, sendo permanente e primordial. No âmbito escolar de ensino formal, a PNEA orienta para que a Educação Ambiental seja integrada nos diversos níveis de educação, passando pela educação básica, superior, especial, profissional e de jovens e adultos. Dessa forma, nota-se que o desenvolvimento de um consumo voltado para a sustentabilidade e de soluções para gestão de resíduos sólidos, devem ser promovidos e incentivados no âmbito educacional, sendo capazes de desenvolver crianças e adultos como cidadãos conscientes, ponto importante para criação de uma população mais participativa na gestão de resíduos (BRASIL, 2010). 
A definição de sustentabilidade é associada a dois entendimentos básicos, a saber: desenvolvimento econômico e sustentabilidade ecológica. O desenvolvimento econômico ecologicamente sustentável pode ser compreendido como um processo de mudanças relacionadas à estrutura, organização e atividade de um sistema econômico ecológico, objetivando o bem-estar da sociedade, a qual pode ser sustentada pelos recursos naturais (CAVALCANTI, 2010).

Sustentabilidade trata-se de um conceito sistêmico, que visa prover todas as necessidades sociais, econômicas, culturais e ambientais para garantia de um futuro melhor. Ou seja, é a maneira inteligente como os recursos naturais são utilizados e protegidos pensando na geração futura. Portanto, seu conceito detalhado quer dizer defensável, suportável, capaz de ser mantido e preservado, se determinadas condições e recursos não forem depletados, ou danificados permanentemente (CAMPOS, 2015).

O princípio de sustentabilidade surge como uma resposta dada pela razão modernizadora e como uma condição para construir uma nova racionalidade produtiva, fundada no potencial ecológico e em novos sentidos de civilização a partir da diversidade cultural do gênero humano. Trata-se da reapropriação da natureza e da invenção do mundo; não só de um mundo no qual caibam muitos mundos, mas de um mundo conformado por uma diversidade de mundos, abrindo o cerco da ordem econômica-ecológica globalizada (LEFF, 2001).

Portanto, a Educação Ambiental é responsável, por compartilhar conhecimentos que podem gerar ações que propiciam a sustentabilidade, cumprindo com todos os requisitos de uma educação para o desenvolvimento sustentável. A Educação Ambiental promove uma conscientização do que realmente pode-se entender sobre o que é sustentabilidade, uma vez que, ao se estudar a o desenvolvimento sustentável deve se visar à educação como base para fundamentar um conceito consciente e que realmente promova a sustentabilidade (ROOS; BECKER, 2012).

A ênfase da Educação para a Sustentabilidade deve estar voltada para que o professor se torne capaz de perceber as relações entre os diferentes componentes curriculares, enfatizando uma formação contextualizada ao nível local e global e a necessidade de enfrentar a lógica da exclusão e das desigualdades. Nessa perspectiva a sala de aula passa a exercer um papel decisivo para o desenvolvimento de discussões que busquem entender e alavancar a sensibilização e tomada de consciência dos alunos, para a resolução de problemas (JACOBI, 2003).

O professor deve adequar as propostas que pretende desenvolver em sala de aula, de maneira a tornar a aprendizagem significativa para o aluno. Deve existir uma profunda relação entre a teoria e prática, para que se estabeleça uma reflexão crítica sobre o que se ensina e se aprende e essa 
reflexão é necessária para que a teoria não se torne sem sentido e a prática uma mera atividade de repetição (FREIRE, 2007).

O aparato legal em prol da disseminação desse precioso conhecimento avançou; cabe aos espaços de interação social se apropriarem e firmarem esse compromisso. No caso específico da escola enquanto espaço formal seu papel é de informar e intermediar descobertas científicas em prol da sustentabilidade, já que de uma forma geral ela é disseminadora de conhecimento. A internalização de conhecimento pode indicar caminhos no sentido da tomada de consciência e mudança de atitudes em prol da minimização da produção de resíduos.

\section{Trajetórias percorridas e possíveis caminhos para o desenvolvimento sustentável}

O surgimento do consumismo desenfreado e desmedido que delineia o comportamento e as atitudes humanas diárias, faz do meio ambiente um grande depósito de resíduos e desta forma, os indivíduos colocam em risco o seu próprio sustento, o que também se revela como alarmante ameaça a sobrevivência das sociedades vindouras, meio a agressões constantes a natureza e, por consequência, a própria vida. Assim, caracteriza-se o atual modelo de sociedade capitalista, que se encontra imersa em uma crise civilizatória e ao ser humano, compete a racionalidade e o consumo consciente dos recursos naturais (TREVISOL, 2013).

Neste sentido, surge no cenário mundial a ideia de sustentabilidade no século XX, por iniciativa da Organização das Nações Unidas (ONU), em 1982, após avaliação dos 10 anos da Conferência que ocorreu em Estocolmo, quando a ONU buscou compreender de que forma as atividades realizadas no mundo, impactam, de alguma forma, na vida do Planeta. Para dar novos rumos a esta situação, a ONU solicitou um relatório a uma equipe de pesquisadores, liderada pela ex-Ministra da Noruega, Dra. Gro Harlen Brundtland, cujos resultados foram apresentados em 1987, passando a ser conhecido como: Relatório de Brundtland (ONU, 2015).

Em 1991 na Comissão Mundial sobre Meio Ambiente e Desenvolvimento, o relatório teve a pretensão de propor estratégias ambientais de longo prazo para obter um desenvolvimento sustentável. Já em 1992 na cidade do Rio de Janeiro realizou-se a Conferência das Nações Unidas sobre o Meio Ambiente e o Desenvolvimento, intitulada também como Cúpula da Terra, Rio 92 ou Eco 92. No ano de 2002, ocorreu em Johannesburgo, na África do Sul, a Cúpula Mundial sobre o Desenvolvimento Sustentável, ou Cúpula da Terra (Rio + 10).

Em 2015, ocorreu em Nova York a Conferência da ONU, onde reuniu representantes de muitas partes do mundo e resultou em uma nova Agenda com 17 Objetivos do Desenvolvimento 
Sustentável (ODS) e mais 163 metas para serem alcançadas até o ano de 2030. Esta Agenda é um plano de ação para as pessoas, o planeta e a prosperidade. Também busca fortalecer a paz universal com mais liberdade. Tendo como propósito servir como plataforma de ação à comunidade internacional e aos governos na promoção da prosperidade comum e do bem-estar para todos ao longo dos próximos 15 anos (ONU, 2015).

A proposta está fundamentada nos tratados internacionais de direitos humanos, na Declaração Universal dos Direitos Humanos, na Declaração do Milênio e no documento final da Cúpula Mundial de 2005. Entre os 17 Objetivos de Desenvolvimento Sustentável traçados para a agenda 2030. Este estudo destaca as ODS 4 e 12, que respectivamente visam: educação de qualidade e consumo e produção responsáveis. A ODS 4 tem como objetivo assegurar a educação inclusiva e equitativa e de qualidade, e promover oportunidades de aprendizagem ao longo da vida para todas e todos e em uma de suas metas é garantir que até 2030 todos os alunos adquiram conhecimentos e habilidades necessárias para promover o desenvolvimento sustentável, inclusive, entre outros, por meio da educação para o desenvolvimento sustentável e estilos de vida sustentáveis, direitos humanos, igualdade de gênero, promoção de uma cultura de paz e não violência, cidadania global e valorização da diversidade cultural e da contribuição da cultura para o desenvolvimento sustentável. A ODS 12 tem como objetivo assegurar padrões de produção e de consumo sustentáveis e tem como uma de suas metas garantir que até 2030, as pessoas, em todos os lugares, tenham informação relevante e conscientização para o desenvolvimento sustentável e estilos de vida em harmonia com a natureza (ONU, 2015).

Mas, para ser sustentável, o desenvolvimento precisa ser ambientalmente correto, socialmente justo, economicamente viável e culturalmente respeitoso das diferenças. Ou seja, tratar sobre sustentabilidade, quer dizer apenas a reduzir impactos ou de abrandar os estragos. Mas a perspectiva de mudança na maneira de enxergar o mundo, e de se relacionar com os demais seres vivos do planeta. Faz-se necessário mudar valores, atitudes e comportamentos individuais e coletivos (GADOTTI, 2009).

Um dos desafios da sustentabilidade ambiental é a conscientização de que este é um processo necessário para manutenção da vida, portanto as trajetórias e os caminhos percorridos até aqui foram fundamentais para buscar estratégias na mediação entre o desenvolvimento socioeconômico e o respeito a natureza, no entanto é necessário que os estudos continuem avançando em prol do desenvolvimento sustentável. 


\section{Considerações Finais}

É preciso debater as questões ambientais nos diversos espaços de convivência social com o intuito de promover um novo pensar, um novo olhar e, consequentemente, esperar novas posturas e práticas cotidianas de cuidado com o meio ambiente. Existe uma disponibilidade de teorias que propõem formas de agir para se adequar às questões ambientais atuais, no entanto, ainda é um desafio lidar e colocar essas diversas informações em prática.

É preciso capacitar profissionais em Educação Ambiental que colaborem e criem possibilidades de confrontar discursos sobre a importância do pensar e agir de forma adequada nos espaços de vivência, bem como democratizar informações que permitam uma reflexão e possam possibilitar a construção de um comportamento mais reflexivo. A partir dessa reflexão espera-se que a apropriação desses saberes possa fomentar novos diálogos, novas descobertas que possam colaborar para transpor barreiras que insistem na incompatibilidade de entender que as ações humanas no meio ambiente geram consequências muitas vezes irreversíveis, o que visivelmente já é perceptível, sendo assim, as ações se fazem urgentes e necessárias.

A PNEA traça orientações políticas e pedagógicas para a educação ambiental e traz conceitos, princípios e objetivos que podem ser ferramentas educadoras para a comunidade escolar formal. A Educação Ambiental, comprometida com a transição para escolas e sociedades sustentáveis deve contribuir para animar e fortalecer cada pessoa em seu compromisso com a manutenção da vida e a preservação da biodiversidade. A Educação Ambiental, em todos os níveis, tem procurado desempenhar esse difícil papel de resgate de valores como o respeito à vida e à natureza.

É censurável o aumento concernente à produção de resíduos e a distância que essa demanda se encontra da coleta seletiva. O que, inclusive, não está de acordo com um dos Objetivos do Desenvolvimento Sustentável, que traz como proposta assegurar padrões de produção e de consumo sustentáveis até 2030 e orienta sobre a necessidade da redução substancial da geração de resíduos por meio da prevenção, redução, reciclagem e reuso. Em síntese é preciso incentivar e encontrar caminhos que possam expandir práticas que venham a culminar no controle da produção de resíduos.

\section{Referências}

ABRELPE. Associação Brasileira de Empresas de Limpeza Pública e Resíduos Especiais Panorama dos resíduos sólidos no Brasil. São Paulo. Disponível em: http://abrelpe.org.br/panorama/. Acesso em: 05 ago. 2019. 
ANDRADE, J. D. N. L. Educação ambiental nas séries iniciais $\left(2^{\circ}\right.$ ao $\left.5^{\circ}\right)$ na Escola Estadual de Ensino Fundamental e Médio João Ribeiro. 2014. 40 f. Trabalho de Conclusão de Curso (Curso de Licenciatura em Geografia) - Pró Reitoria de Ensino Médio, Técnico e Educação à Distância, Universidade Estadual da Paraíba, Campina Grande, 2014.

BRASIL. Lei $\mathrm{n}^{\circ}$ 12.305, de 2 de agosto de 2010. Institui a Política Nacional dos Resíduos Sólidos; altera a Lei n ${ }^{\circ}$ 9.605, de 12 de fevereiro de 1998; e dá outras providências. Diário Oficial [da] República Federativa do Brasil, Poder Executivo, Brasília, DF, 02 ago. 2010.

BRASIL. Ministério da Educação. Conselho Nacional da Educação. Resolução ${ }^{0} 2$ de 15 de junho de 2012. Estabelece as diretrizes curriculares nacionais para a educação ambiental, Brasília, DF. 2012.

CAMPOS, A. C. S.; ESTENDER, A. C.; MACEDO, D. O Ambiente e a Sustentabilidade no Ramo Hoteleiro. Revista de Administração do UNISAL, São Paulo, v. 5, n. 7. 2015.

CAVALCANTI, C. Concepções da economia ecológica: suas relações com a economia dominante e a economia ambiental. Estudos Avançados, São Paulo, v. 24, n. 68, p. 53-67. 2010.

DIAS, G. F. Educação Ambiental: princípios e práticas. 7. ed. São Paulo: Gaia, 2001.

FREIRE, P. Pedagogia da autonomia: saberes necessários à prática educativa. São Paulo: Paz e Terra, 1996.

FREIRE, M. A. Educação para a Sustentabilidade: Implicações para o Currículo Escolar e para a Formação de Professores. Pesquisa em Educação Ambiental, São Paulo, v. 2, n. 1, p. 141-154. 2007.

FERREIRA, N. S. C. Gestão Democrática de Educação: atuais tendências, novos desafios. 7 ed. São Paulo: Cortez, 2011.

GADOTTI, M. Educação integral no Brasil: inovações em processo. São Paulo: Instituto Paulo Freire, 2009.

HUSS, A. C.; SALOMÃO, G.M.; COSTA, M.P. Obsolescência programada e o direito do consumidor. Revista Jurídica da UniFil, [S.l.], v. 14, n. 14, p. 71-80, jun. 2019.

JACOBI, P. Educação ambiental, cidadania e sustentabilidade. Cad. Pesquisa, São Paulo, n. 118, p. 189-206, 2003.

LIMA, G.F.C. Consumo e Resíduos Sólidos no Brasil: as contribuições da Educação Ambiental. Revista Brasileira de Ciências Ambientais, n. 37, p.47-57, set. 2015.

LOGAREZZI, A. Contribuições conceituais para o gerenciamento de resíduos sólidos e ações de educação ambiental. In: JUNIOR, Antônio Thomaz et al. Resíduos sólidos no pontal do Paranapanema. Presidente Prudente: UNESP, 2004. p. 219-246.

LOURENÇÃO, C.; RASNHESKI, F.; MACHADO, F. I. Escolas do Campo: caminhos possíveis para a superação da lógica capitalista / Rural Schools: possiblewaystoovercomecapitalistlogicv. Educação em Foco, Belo Horizonte, v. 22, n. 37, p. 133.150, mai./ago. 2019.

LEFF, E. Complexidade, interdisciplinaridade e saber ambiental. In: PHILIPPI Jr., A., TUCCI, C. E. M.; HOGAN, D. J.; NAVEGANTES, R. (Orgs). Interdisciplinaridade em Ciências Ambientais. São Paulo: Signus Editora, 2000. p. 19 -51.

LEFF, E. Saber ambiental: sustentabilidade, racionalidade, complexidade, poder. Petrópolis: Vozes, 2001. 
MACEDO, M.A.; RAMOS, M.C. Educação Ambiental e Resíduos Sólidos Urbanos: Caminho para um Futuro Sustentável. Eduser - Revista de Educação, v. 7, n. 2, 2015.

OLIVEIRA, K. A.; CORONA, H. M. A percepção ambiental como ferramenta de propostas educativas e de políticas ambientais. Revista Científica ANAP Brasil, v. 1, n. 1, jul. 2008.

ONU. Organização das Nações Unidas. Transformando Nosso Mundo: A Agenda 2030 para o Desenvolvimento Sustentável. 2015. Disponível em: <https://nacoesunidas.org/onu-no-brasil>. Acesso em: 07 set. 2019.

ONU. Organizações Nações Unidas. 2018. Disponível em: <https://brasil.un.org/pt-br/81186humanidade-produz-mais-de-2-bilhoes-de-toneladas-de-lixo-por-ano-diz-onu-em-dia-mundial $>$. Acesso em: 08 nov. 2019.

ROOS, A.; BECKER, L. S. B. Educação ambiental e sustentabilidade. Revista Eletrônica em Gestão, educação e Tecnologia Ambiental, Santa Maria, v. 5, n. 5, p. 857-866. 2012.

TREVISOL, J. V.; SORRENTINO, M. A Educação Ambiental em uma Sociedade de Risco: tarefas e desafios na construção da sustentabilidade. 1. ed. Joaçaba: UNOESC, 2013.

VERGARA, S.C. Projetos e Relatórios de Pesquisa em Administração.12. ed. São Paulo: Atlas, 2010.

Recebido em: 14/05/2020

Aprovado em: 30/12/2020 